\author{
Metals and Ceramics Division
}

EVALUATION OF SIALON INTERNAL COMBUSTION ENGINE COMPONENTS AND

FABRICATION OF SEVERAL CERAMIC COMPONENTS

FOR AUTOMOTIVE APPLICATIONS

C. H. McMurtry

M. O. Ten Eyck

Date Published: October 1992

NOTICE: This document contains information of a preliminary nature. It is subjest to revision or correction and therefore does not represent a final report.

Prepared for

U.S. Department of Energy

Assistant Secretary for Conservation and Renewable Energy

Office of Transportation Technologies

Advanced Materials Development Program

EE 5101000

Prepared by the

OAK RIDGE NATIONAL LABORATORY

Oak Ridge, Tennessee 37831-6285

managed by

MARTIN MARIETTA ENERGY SYSTEMS, INC.

for the

U.S. DEPARTMENT OF ENERGY

under contract DE-AC05-84OR21400 
CONTENTS

Page

LIST OF FIGURES $\ldots \ldots \ldots \ldots \ldots \ldots \ldots \ldots \ldots \ldots \ldots \ldots \ldots \ldots \ldots, \quad \mathbf{v}$

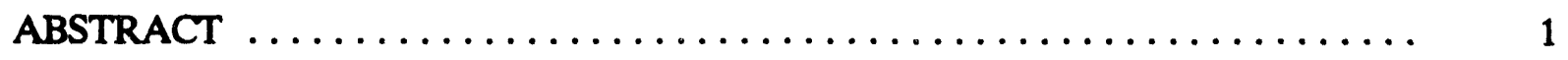

1. INTRODUCTION $\ldots \ldots \ldots \ldots \ldots \ldots \ldots \ldots \ldots \ldots \ldots \ldots \ldots \ldots \ldots \ldots \ldots \ldots \ldots$

2. DEVELOPMENT WORK $\ldots \ldots \ldots \ldots \ldots \ldots \ldots \ldots \ldots \ldots \ldots \ldots \ldots \ldots \ldots \ldots \ldots$

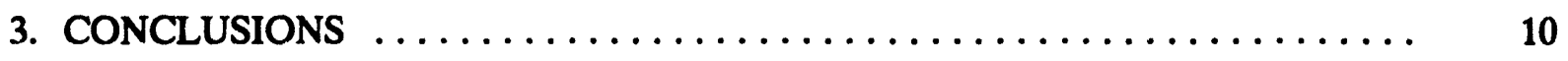

4. ACKNOWLEDGMENTS $\ldots \ldots \ldots \ldots \ldots \ldots \ldots \ldots \ldots \ldots \ldots \ldots \ldots \ldots \ldots \ldots \ldots \ldots$ 


\section{LIST OF FIGURES}

Figure $\quad$ Page

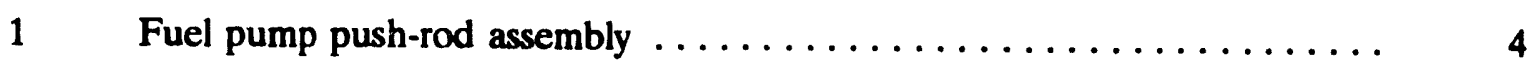

2 Uniaxial compaction and die wall-friction measurement apparatus ...... 5

$3 \quad$ Sectioned Sialon push-rod tips $\ldots \ldots \ldots \ldots \ldots \ldots \ldots \ldots \ldots \ldots \ldots \ldots \ldots \ldots$

$4 \quad$ Push-rod tip design evaluation $\ldots \ldots \ldots \ldots \ldots \ldots \ldots \ldots \ldots \ldots \ldots, 9$

$5 \quad$ Fuel pump push-rod tip assembly $\ldots \ldots \ldots \ldots \ldots \ldots \ldots \ldots \ldots \ldots \ldots \ldots$ 


\title{
EVALUATION OF SIALON INTERNAL COMBUSTION ENGINE \\ COMPONENTS AND FABRICATION OF SEVERAL CERAMIC COMPONENTS FOR AUTOMOTTVE APPLICATIONS*
}

\author{
C. H. McMurtry ${ }^{\dagger}$ and M. O. Ten Eyck ${ }^{\dagger}$
}

\begin{abstract}
Fabrication development work was carried out on a push-rod tip having a stepped OD design and a $90^{\circ}$ shoulder in the transition area. Spray-dried Sialon premix was used in dry press tooling, and components were densified to about 98\% of theoretical density using pressureless sintering conditions. Upon evaluation of the sintered components, it was found that all components showed defects in the transition area. Modifications of the pressing parameters, incorporation of a $45^{\circ}$ angle in the shoulder area, and the use of tailored premix did not lead to the fabrication of defect-free parts. From these observations, it was concluded that the original part design could not easily be adapted to highvolume ceramic manufacturing methods.

Subsequently, a modification to the design was implemented. An SiC material with improved toughness (Hexoloy SX) was used for fabricating several test components with a closely machined, straight OD design. Pressurelesssintered and post-hot isostatically pressed (HIPed) Hexoloy SX components were supplied to The American Ceramic Engine Company (ACE) for assembly and testing. Fuel pump push-rod assemblies with Hexoloy SX tips were prepared by ACE, but no testing has been carried out to date.
\end{abstract}

\section{INTRODUCTION}

The component selected for this program* was a fuel pump push-rod tip, and the initial material selected was Sialon. Parts produced to final dimensions were to be dynamometer and engine tested by The American Ceramic Engine Company (ACE).

The program was divided into three tasks as follows:

Task 1: Fabrication of Sialon Components - Carborundum:

- fabrication of fuel pump push-rod tips,

- use of Carborundum's Sialon composition,

* Research sponsored by the U.S. Department of Energy, Assistant Secretary for Conservation and Renewable Energy, Office of Transportation Technologies, as part of the Ceramic Technology for Advanced Heat Engines Project of the Advanced Materials Development Program, under contract DE-AC05-84OR21400 with Martin Marietta Energy Systems, Inc.

tThe Carborundum Company, Technology Division, P.O. Box 832, Niagara Falls, New York 14302. 
- dry pressing of a spray-dried Sialon premix, and pressureless sintering to net shape.

Task 2: Evaluation of Components - ACE:

Wear-rate testing of several components:

- 20-h testing of several representative samples in a high-speed spin fixture at speeds representative of race car engines,

- installation in a race car engine and dynamometer testing, and

- installation in several racing car applications.

Task 3: Preparation of a Report Summarizing the Test Results - Carborundum:

- $60 \mathrm{~d}$ after completion of Task 2, submit draft of final report for approval.

During the course of carrying out development under Task 1, it was determined that components of the initial design could not be fabricated in a high-volume process without any defects. Also, during this period, Carborundum had initiated the development of Hexoloy SX $\mathrm{SiC}$. This material offers the potential to meet the requirements for valve train applications at a lower cost than Sialon. A revised statement of work agreed to on December 13, 1991, addressed the redesign and fabrication of the push-rod tip and also focussed on Hexoloy SX rather than Sialon:

\section{Revised Statement of Work}

Task 1: Fabrication of Hexoloy SX and SA Components - Carborundum:

- fabrication of straight fuel push-rod tips;

- use of Carborundum's SiC compositions (Hexoloy SX, Hexoloy SA);

- isostatic pressing and green machining of spray-dried premix;

- sintering and grinding to 0.001-in. tolerance; and

- delivery of 10 Hexoloy SX and 10 Hexoloy SA parts.

Task 2: Evaluation of Components - ACE:

- tribological testing, and

- dynamometer testing.

Task 3: Preparation of a Report Summarizing the Test Results - Carborundum:

- $60 \mathrm{~d}$ after completion of Task 2, submit draft of final report for approval. 


\section{DEVELOPMENT WORK}

\section{Task 1: Fabrication of Sialon Components}

The fabrication work was to be based on Carborundum's spray-dried Sialon composition and the company's dry-pressing capabilities using a fuel pump push-rod tip designed by ACE. Figure 1 depicts the fuel pump rod assembly with the ceramic push-rod tips in place.

A large lot of spray-dried premix (seve al hundred pounds) of a water-processable Sialon composition had been prepared in October 1989 using standard-production, powder-processing equipment. A modulus of rupture (MOR) strength at room temperature of $94 \mathrm{ksi}$ with a Weibull modulus of 12.7 was obtained on bars cut from isopressed, green-machined, and pressurelesssintered test plates. A large quantity of this premix had previously been successfully used to fabricate a variety of shapes from isopressed stock.

To carry out this program, $50 \mathrm{lb}$ of the as-spray-dried premix were screened through a 70-mesh sieve to remove coarse agglomerates. This lot, designated as WL-23, was characterized using sieve analysis (see Table 1) and moisture content. Additional rheological information was obtained by using a uniaxial compaction and die wall-friction measurement apparatus (Fig. 2) to determine peak ejection force, friction during dry pressing, and green compressive strength. This apparatus and its corresponding software have been developed internally for the general use of assessing premix quality as it pertains to dry-pressing behavior. Shrink factors for designing drypress tooling were estimated on pressureless-sintered water pump seals that had been dry pressed to $58 \%$ of theoretical density. A sintered bulk density of $98.5 \%$, based on a theoretical density of $3.26 \mathrm{~g} / \mathrm{cc}$, was achieved with a diameter shrinkage of $17.7 \%$.

Steel dry-press tooling with tungsten carbide wear inserts was designed for a 4-ton automatic press with multipunch capability. Initial tooling setup evaluation was conducted using three different green densities. Both dimensional and density evaluations were used to assess quality after sintering. It was found that both diameters could be obtained within drawing tolerances using the higher green density. However, in all cases, both height dimensions were found to be substantially undersized. This observation was traced back to a fill characteristic of the premix. This Sialon premix, especially when using a relatively narrow but deep die cavity, showed a relatively low packing density in comparison to that anticipated from the previously mentioned dry-pressing run of waterpump seals. 
高

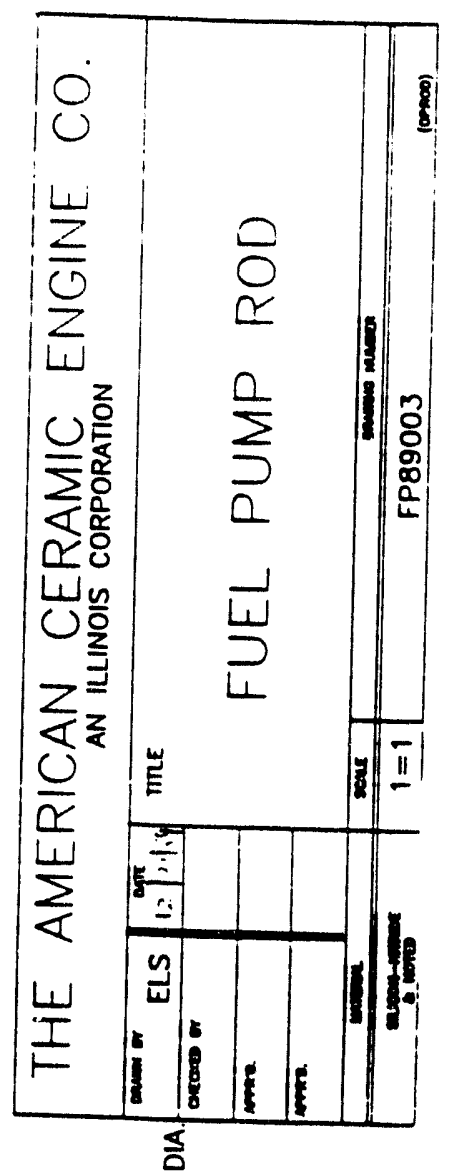

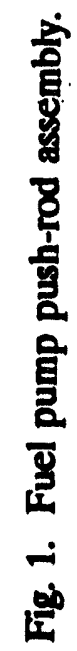

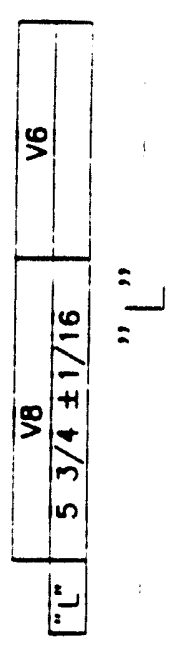

$n$
0
0
+1
0
$\stackrel{n}{N}$
0

is

×觜

है?

崖忽

崖岗。

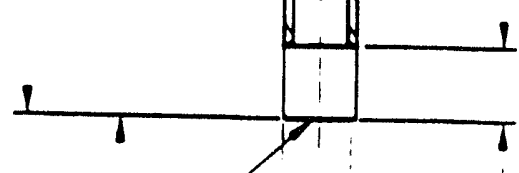

농요 늘

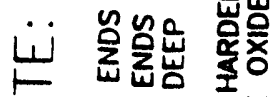

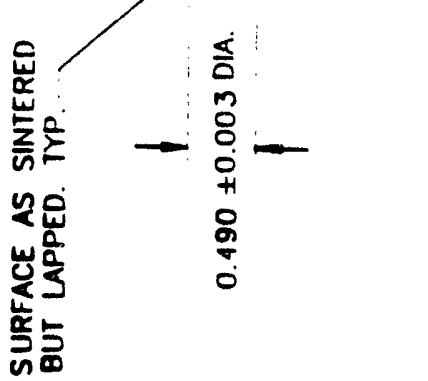

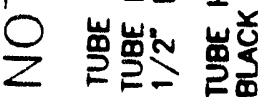



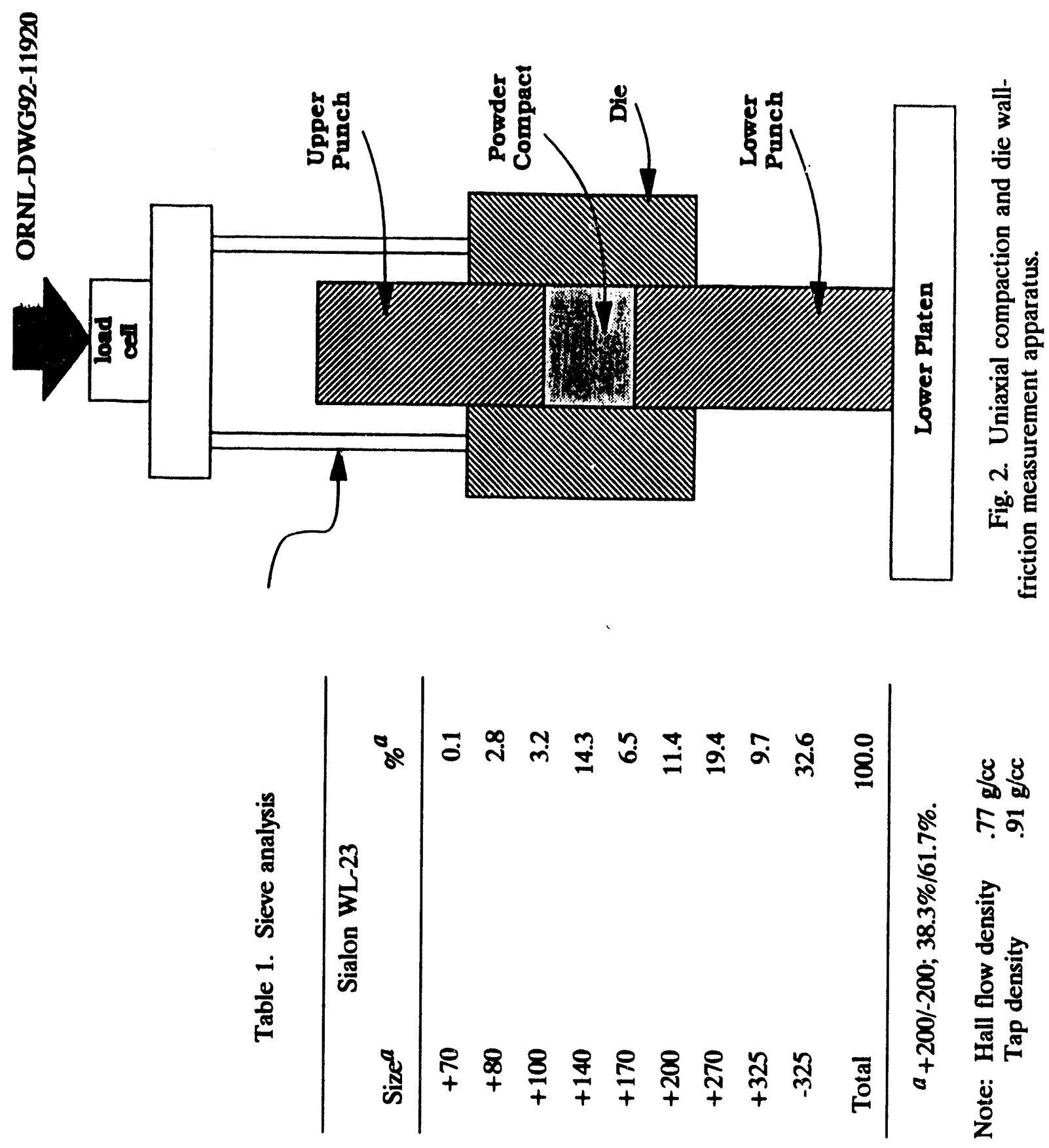
Further visual investigation of the sintered Sialon push-rod tips showed that all exhibited a circumferential crack in the transition section between the large and small diameters. The Hexoloy SA components, which were pressed for comparison reasons, appeared visually to be crack free. Additional pressing trials were conducted to assess the influence of press setup, as well as precompaction and hold-down pressure, on the height shrink factors and the formation and location of the circumferential crack. The various groups of green and sintered push-rod tips were also evaluated with respect to dimensional compliance. Assessment of the push-rod tip heights showed that none of the pressing conditions used provided sufficient overall green height to meet the finished height requirement of $0.500+0.020$ in. It was concluded that the die cavity, whose design principles were based on historic data from Hexoloy SA premix, was too short to accommodate the necessary premix volume. Independent of the pressing conditions used, all Sialon components continued to exhibit a noticeable crack in the transition area while, by comparison, the Hexoloy SA components pressed in this tooling appeared to be visually free of these cracks. These differences were attributed to the rheology of the two premixes.

As a result of discussions between Oak Ridge National Laboratory, Carborundum, and ACE, it was decided to modify the original dry-pressing tool and incorporate a $45^{\circ}$ angle instead of the $90^{\circ}$ angle with a 0.024 -in. fillet radius in the transition area. It was believed that this modification should lead to a more gradual green density variation in the transition area and would therefore reduce the high stresses that caused cracking in this area. However, it was found that the crack pattern became more pronounced on all premix candidates evaluated. Even the Hexoloy SA components showed cracks that could easily be detected visually.

Subsequently, new dry-pressing tooling was designed having the original $90^{\circ}$ shoulder angle with a 0.024 -in. radius in the transition area but with a deeper cavity to accommodate more premix during the initial filling cycle and, in turn, meet the overall height requirement of $0.5 \mathrm{in}$. after sintering. Components with selected green densities were pressed and overpressure sintered to $99.0+\%$ of theoretical density. Good height and diameter control was achieved. However, upon closer inspection, all parts exhibited the same circumferential cracks as previously observed.

Several sintered push-rod tips were sectioned to further investigate the nature of this circumferential crack (Fig. 3). Additional evaluations with respect to position and angle of the observed crack and its dependence on press settings (pressure distribution, location of the neutral zone, etc.) were conducted. However, all the Sialon components sectioned and evaluated showed a similar crack pattern. An indepth evaluation of the Hexoloy SA components, pressed in this tooling, showed them to be better than the Sialon components although, frequently, minor cracking was still detected in the transition area. 

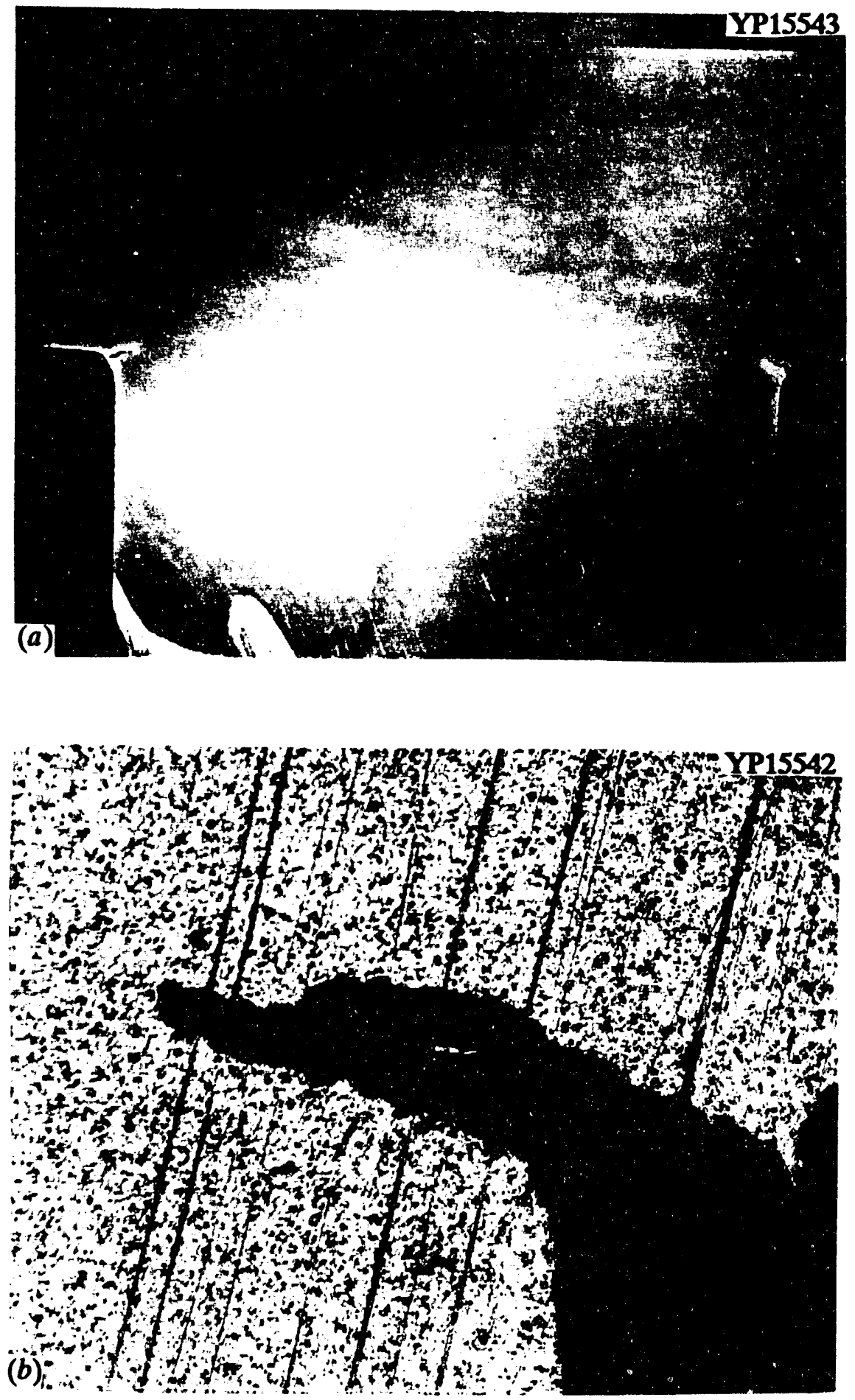

Fig. 3. Sialon push-rod tips sectioned longitudinally showing defects in iransition zone. (a) 10X, (b) 150X. 
The rheology of the Sialon premix was therefore reevaluated and compared with standard $\mathrm{SiC}$ premix. It was found that the Sialon premix exhibited a higher fracture strength but had a significantly higher stiffness (elastic modulus) and also required higher ejection forces during the removal from the die. The latter makes this Sialon premix more susceptible to brittle behavior during spring-back or less tolerant to small density variations within the part, especially in the transition region.

Attempts were made to make the existing Sialon premix more pliable through the addition of lubricants to achieve better release from the pressing die during ejection. Also, various premix particle-size fractions and particle-size combinations were selected in an attempt to achieve more uniform green densities. None of these modifications resulted in flaw-free components.

Subsequently, test batches of Sialon premix with more pliable binder systems were prepared and evaluated using the uniaxial compaction and die wall-friction measurement apparatus. The material that showed the least ejection force after pressing was scaled-up to a 50-lb lot.

New pressing trials were conducted using three different materials: Sialon, Hexoloy SA, and a new experimental SiC material (Hexoloy SX) which utilizes $\mathrm{Al}$ - and $\mathrm{Y}$-compounds as sintering additives. It was found again that all sialon components exhibited a crack in the transition area, while only some of the Hexoloy SX components and none of the Hexoloy SA components exhibited visually apparent cracks. Upon closer inspection of sectioned components from the three material systems, it became apparent that most components showed similar crack development. However, the extent of cracking varied depending on the material system and the pressing conditions used. This is believed to be a result of subtle variations in the rheological behavior of these premixes.

\section{Revised Task 1: Fabrication of Hexoloy SX and SA Components}

The revised statement of work and its corresponding tasks were to address the fabrication of push-rod tips (Fig. 4) with a closely controlled OD $(0.378+-0.0005$ in.) for shrink fitting within a closely machined metal push rod. It is believed that the straight design is more suitable for high volume, cost-effective manufacturing than the stepped design. The surface finishing requirements on the wear surface from the original push-rod tip design were maintained as a lapped finish. Pressureless-sintered Hexoloy SA push-rod tips were to be fabricated concurrently with two groups of Hexoloy SX components, namely pressureless-sintered and pressurelesssintered plus post-hot isostatically pressed (HIPed) components, since the latter provides improved density that could prove to be beneficial in this high-performance application. 

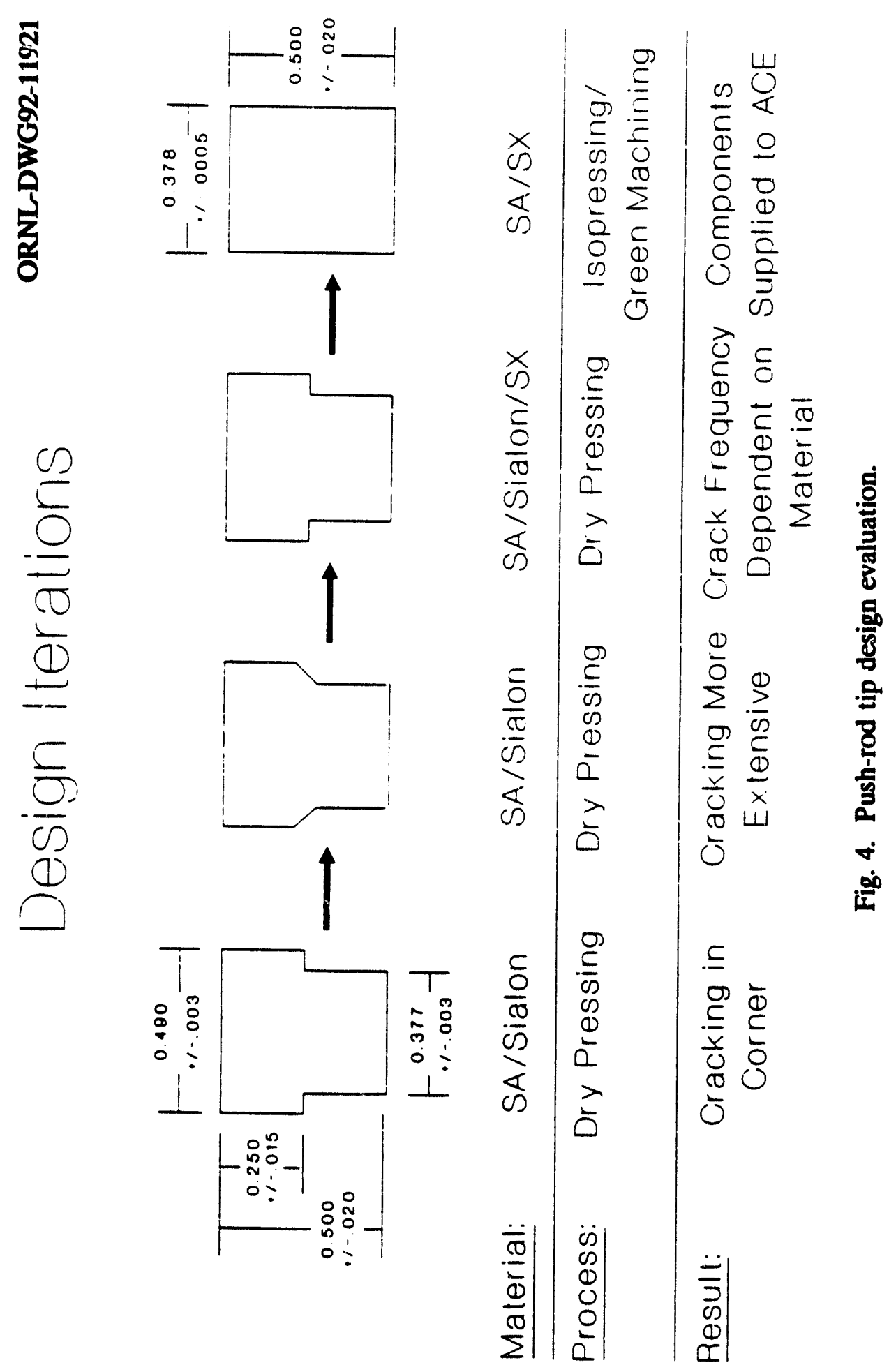
Spray-dried premix lots for each of the two chosen material systems were prepared in the production equipment using the same $\mathrm{SiC}$ grain. The premix was isostatically pressed into logs and subsequently green machined into individual components incorporating sufficient stock for finish grinding. The Hexoloy SA components were pressureless sintered to $97 \%+$ of theoretical density. Sintering of the Hexoloy SX components resulted initially in lower-than-expected sintered densities (95 to $96 \%$ of theoretical density). A post-HIPing treatment was used to enhance densification to $\mathbf{9 8 . 5}$ to $99.1 \%$ of theoretical density. Hexoloy SA and post-HIPed Hexoloy SX components were ground to size, and the wear surface was lapped to a surface finish of $\mathrm{Ra}<0.2 \mu \mathrm{m}$. Additional analyses of the surface measurements showed that $\mathrm{Rz}<2 \mu \mathrm{m}$ and $R \max <5 \mu \mathrm{m}$ werc obtained. The finished components were subjected to standard dimensional and fluorescent penetrant inspection. Ten pressureless-sintered Hexoloy SA and 10 post-HIPed Hexoloy SX components meeting all quality assurance criteria were supplied to ACE in late August 1991 for their testing.

Modifications to the sintering conditions were successful in increasing the density of pressureless-sintered Hexoloy SX push-rod tips to $97 \%+$ of theoretical density. Subsequently, these components were finish ground, lapped, and inspected to the same specifications as the earlier parts. Ten components were submitted to ACE in mid-October 1991.

ACE prepared several fuel pump push-rod assemblies; one was returned to Carborundum for visualization, and the remaining two were to be used for testing and performance evaluation. To date, no test results have been received.

Figure 5 shows a complete fuel pump push-rod assembly (steel tube with two ceramic end inserts) and two machined (right) and one as-sintered (top) Hexoloy SX push-rod tips. A metric MOR bar (50 mm long) is depicted for size relationship.

\section{CONCLUSIONS}

The development activity to fabricate ceramic fuel pump push-rod tips reinforced the importance of an iterative process loop between the end user, designer, and fabricator. While the original design was very difficult to fabricate using established high-volume processing technology, the redesigned component, which has improved fabricability, appears to also offer equivalent performance. Lower processing costs would be expected to result in lower component costs due to an anticipated increase in process yields. The introduction of a lower-cost material, Hexoloy SX, is also expected to have a positive impact on the economics. 


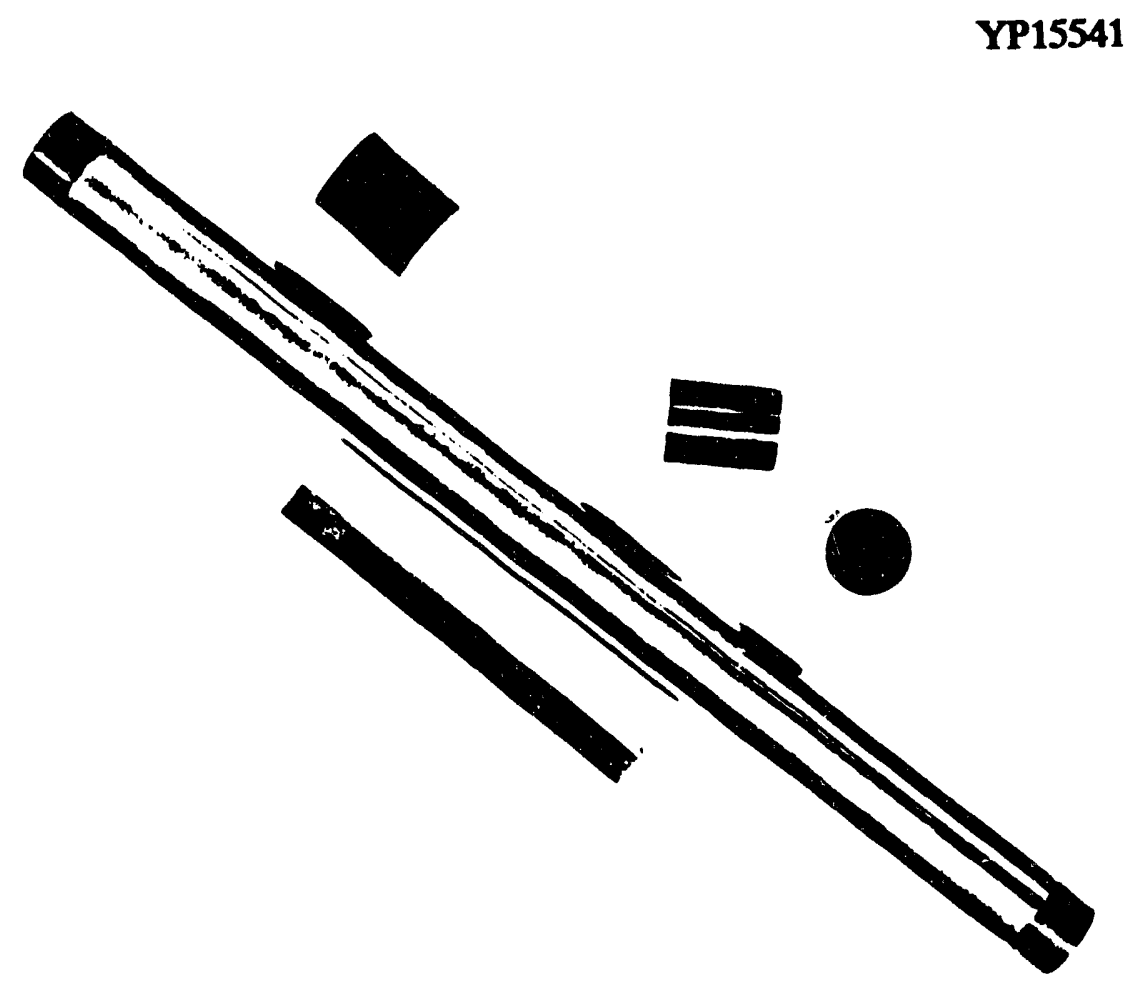

Fig. 5. Fuel pump push-rod tip assembly.

The testing phase of this program is incomplete, and both laboratory and engine testing are still required to establish the performance standards for the ceramic components relative to the current metal parts. As that experience is gained in the push-rod tip, as well as other applications, Carborundum is positioned to pursue the cost-effective scale-up of Hexoloy SX manufacturing for automotive components.

\section{ACKNOWLEDGMENTS}

The authors thank M. R. Upton for final report preparation and K. Spence for editing. 
ORNL/M-2253

\section{INTERNAL DISTRIBUTION}

1-2. Central Research Library

3. Document Reference Library

4-5. Laboratory Records Department

6. Laboratory Records, ORNL RC

7. ORNL Patent Section
8-10. M\&C Records Office

11. R. A. Bradley

12. D. R. Johnson

13. E. L. Long, Jr.

14. S. G. Winslow

\section{EXTERNAL DISTRIBUTION}

15. ARGONNE NATIONAL LABORATORY, 9700 South Cass Avenue, Technology Division, Building 362-2B, Argonne, IL 60439

B. Larsen

16-26. THE CARBORUNDUM COMPANY, Technology Division, P.O. Box 832, Niagara Falls, NY 14302

T. P. DeAngelis

H. C. McMurtry (5)

M. O. Ten Eyck (5)

27. THE CARBORUNDUM COMPANY, Structural Ceramics Division, P.O. Box 1054, Niagara Falls, NY 14302

J. W. MacBeth

28-29. THECARBORUNDUM COMPANY, Technology Division, P.O. Box 337 Niagara Falls, NY 14302

R. S. Storm

30-31. U.S. DOE, OFFICE OF TRANSPORTATION MATERIALS, CE-34, Forrestal Building, Washington, DC 20585
J. J. Eberhardt
R. F. Schulz

32. U.S. DOE OAK RIDGE FIELD OFFICE, P.O. Box 2001, Oak Ridge, TN 37831

Assistant Manager for Energy Research and Development

32-33. U. S. DOE, OFFICE OF SCIENTIFIC AND TECHNICAL INFORMATION, P.O. Box 62, Oak Ridge, TN 37831

For distribution by microfiche as shown in DOE/OSTI-4500,

Distribution Category UC-332 (Ceramics/Advanced Materials) 

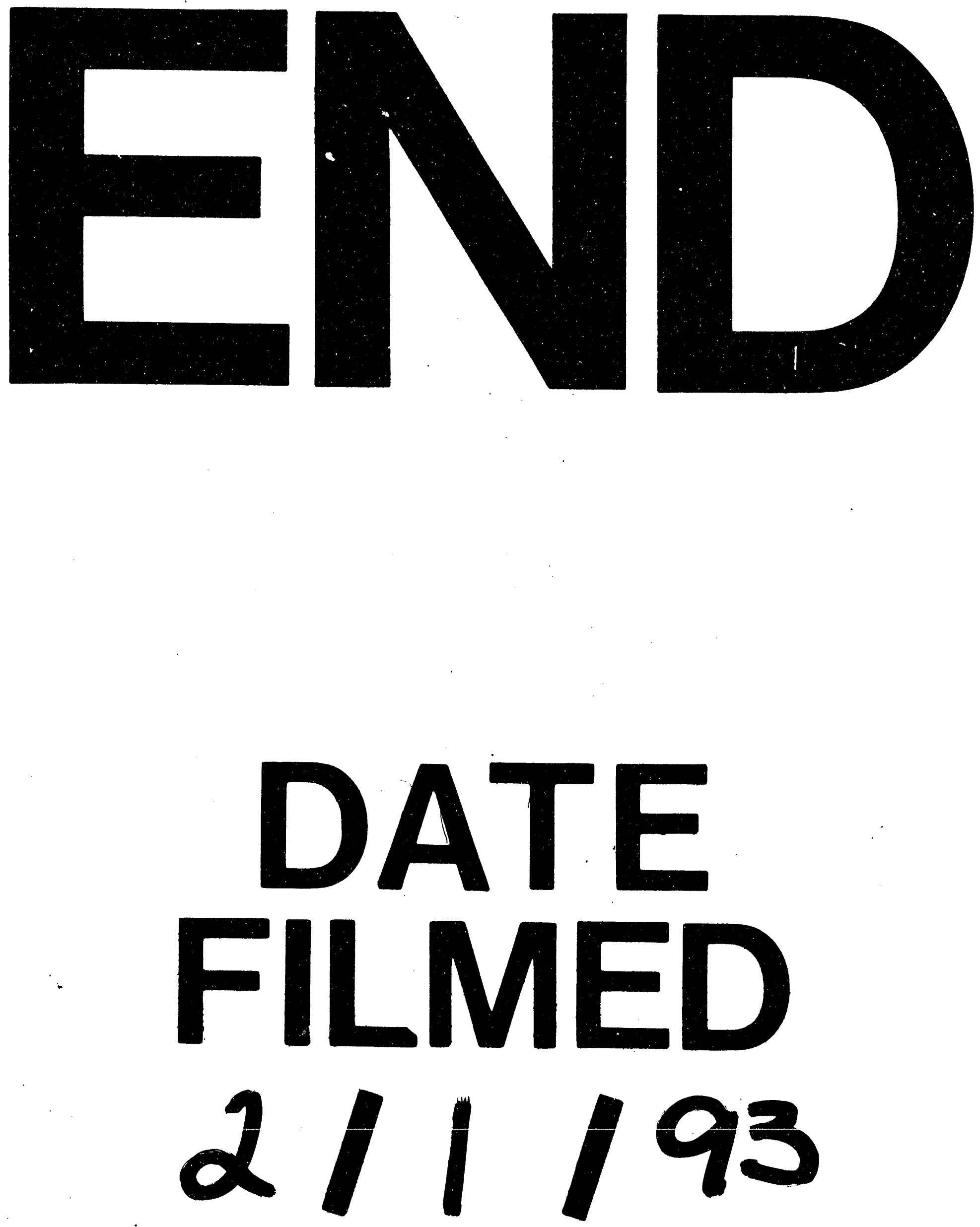
